\title{
Influence of thermal and mechanical fatigue on the shear bond strength of different all-ceramic systems
}

\author{
Hugo-Alberto Vidotti ${ }^{1}$, Jefferson-Ricardo Pereira ${ }^{2}$, Elizeu Insaurralde ${ }^{3}$, Luiz F. Plaça ${ }^{4}$, José R. Delben ${ }^{5}$, \\ Accácio-Lins do Valle ${ }^{6}$ \\ ${ }^{1}$ Department of Prosthodontics, University of São Paulo, Bauru, SP, Brazil \\ ${ }^{2}$ Department of Prosthodontics, University of Southern Santa Catarina, Tubarão, SC, Brazil \\ ${ }^{3}$ Department of Prosthodontics and Restorative Dentistry, School of Dentistry, University of South Mato Grosso, Campo Grande, \\ MS, Brazil \\ ${ }^{4}$ Department of Physics, Center of Exact Sciences and Technology, University of South Mato Grosso, Campo Grande, MS, Brazil \\ ${ }^{5}$ Department of Physics, Center of Exact Sciences and Technology, University of South Mato Grosso, Campo Grande, MS, Brazil \\ ${ }^{6}$ Department of Prosthodontics, University of São Paulo, Bauru, SP, Brazil
}

Correspondence:

University of Southern Santa Catarina, Tubarão, SC, Brazil

Address: Rua Recife 200 - Apto 601 -

Bairro Recife - CEP: 88701-420

jeffripe@rocketmail.com

\section{Abstract}

Background: To evaluate the influence of thermal and mechanical fatigue on the shear bond strength of different all-ceramic cores and veneering porcelain interfaces.

Material and Methods: All-ceramic systems tested were lithium disilicate and zirconia veneered by layering technique. Sixty specimens $(n=20)$ were subjected to shear bond strength. Ten of them were thermal and mechanical cycled. Fracture analysis was performed with stereomicroscopy and scanning electron microscopy. Energy dispersive X-ray spectroscopy analysis was performed across core/veneer interfaces.

Results: Thermal and mechanical cycling did not influence on bond strength. However, there was significant difference among systems $(<0.01)$. CoCr group presented the highest values, followed by lithium disilicate, and zirconia. Failure modes were predominantly adhesive for $\mathrm{CoCr}$, cohesive in core for lithium disilicate, and cohesive in veneer for zirconia. Energy dispersive X-ray showed interaction zone for $\mathrm{CoCr}$ and lithium disilicate groups and was inconclusive for zirconia. Fatigue had no influence on bond strength of groups tested.

Conclusions: The results suggest that there is a chemical bond between core and veneer materials for $\mathrm{CoCr}$ and lithium disilicate groups.

Key words: Ceramics, electron microscopy, fatigue, mechanical stress, shear bond strength. 


\section{Introduction}

Lithium disilicate, a reinforced glass ceramic, and yttriastabilized tetragonal zirconia polycrystalline (YTZ-P) have been widely used as materials for core of bilayered restorations (1).

The bonding between core and veneer material has an important role to success of all-ceramic restorations. Indeed, resistance to outbreak and growth of a flaw on all ceramic restoration is multifactorial and also depends on the materials composition, thickness and design of the restoration, luting techniques, residual stresses induced by the thermal processing or polishing and differences of elastic module of the restoration components (2). Clinically, one of the technical complications reported in the YTZ-P reconstructions is chipping or delamination of the veneering porcelain $(3,4)$ and fractographic analysis from clinical failure shows that the crack origin of some fractured restorations was located at the core veneer interface (5). The estimated stress at failure for delamination $(26.8 \mathrm{MPa})$ is higher than the calculated zirconia veneer bond strength reported in previous studies using bond strength test (15-24 MPa) $(6,7)$, and suggests that the core-veneer interface is a critical factor for the success of layered restorations.

Studies have focused on the bond strength of different ceramic core/veneer combinations and suggest that lithium disilicate have higher bond strength to veneering porcelain compared to zirconia (8-11). However, the performance of this interface when subjected to thermal and mechanical induced stresses, like chewing and ingesting hot food or cold drink, is not yet well understood (12-14).

Spectroscopy analyses are useful tools for the interface characterization of inorganic materials. Morphological and elemental composition of the metal-ceramic interfaces by Scanning Electron Microscopy (SEM) and X-ray Energy Dispersive Spectroscopy (EDS) analysis operating in line scan mode is well described in literature $(15,16)$ and had an important rule on the understanding of bonding mechanisms and atomic diffusion between these materials during sintering process. On the other hand, little information is available regarding all-ceramic materials interfaces. SEM, Confocal Raman Spectroscopy and EDS data strongly suggests that there is an interdiffusion zone at YTZ-P/veneer ceramic interface (17-19). There is not, to the authors' knowledge, such data regarding lithium disilicate core/veneer interface on the literature. Since the influence of thermal and mechanical cycling in conjunction have also not yet been reported, the objective of this study was to investigate the influence of thermal and mechanical cycling on the shear bond strength of YTZ-P and lithium disilicate ceramic and their veneering ceramic and to compare the results to a metal-ceramic system.

\section{Material and Methods}

Following the appropriate University Human Research Ethics Board approval, all-ceramic substructure materials tested were pressed lithium disilicate (LD) (IPS e.max Press, Ivoclar Vivadent, Schaan, Liechtenstein) and yttrium-stabilized zirconium oxide (Y-TZP) machined by the CAD/CAM technique (IPS e.max ZirCAD, Ivoclar Vivadent, Schaan, Liechtenstein) $(n=20)$. A glass-ceramic veneer (IPS e.max Ceram) was used for layering of the all-ceramic core materials. An additional metal ceramic alloy (CoCr) (Fit Cast CoCr, Talladium, Valencia, EUA) was used as control and layered with a compatible glass ceramic veneer (IPS Inline, IvoclarVivadent, Schaan, Liechtenstein) $(n=20)$. Table 1 shows the materials used and their chemical composition. The shear bond strength samples and the results of the Y-TZP and the metal-ceramic groups were part of a previous study performed by our group (20).

A cylindrical stainless steel matrix was used for specimen preparation. The same matrix was used for ceramic layering and shear strength testing. The matrix had a central hole with $6.5 \mathrm{~mm}$ in depth and $6.0 \mathrm{~mm}$ in diameter. A disc ( $6.0 \mathrm{~mm}$ in diameter; $2 \mathrm{~mm}$ thick) was used as a spacer to standardize the veneer layer thickness.

The wax patterns were made with the disc positioned inside the perforation. The wax was liquefied at $75^{\circ} \mathrm{C}$ and flowed with the aid of a dropper into the perforation. After wax cooling, the patterns were removed by the introduction of the metallic pin in an auxiliary perforation and stored in water until the investment and casting or pressing procedures. For the ZirCAD groups a wax pattern was scanned and patterns were milled in a CAD/CAM system (Cerec InLab, Sirona, Bensheim, Germany).

Veneering was carried out with layering technique as per manufacturer's instructions for mass preparation, condensing, baking temperature and time.

Half of the specimens from each group $(n=10)$ were subjected to both thermal and mechanical cycling. The other half (10 from each group) were stored in distilled water for $24 \mathrm{~h}$ at $37^{\circ} \mathrm{C}$ prior to shear bond strength test. The specimens were first thermocycled for 6000 cycles between 5 and $55^{\circ} \mathrm{C}$ in deionized water (Elquip, São Carlos, Brazil) with dwell time of $15 \mathrm{~s}$ and transfer time of $5 \mathrm{~s}$. After that, specimens were mechanical cycling in aqueous environment at $37^{\circ} \mathrm{C}$ with a mechanical cycling machine (Elquip, São Carlos, Brazil) with $3.2 \mathrm{~mm}$ diameter indenter inducing $50 \mathrm{~N}$ load for 20,000 times with a frequency of 1 cycle per second. The loading was applied axially on the center of the porcelain portion of the specimen.

The samples were positioned into the matrix with the disc at the bottom of the perforation, leaving the ceramic layer visible outside the matrix, such that the shear forces could only be applied at the interface. Shear strength tes- 
Table 1: Different materials used in this study, chemical composition and physical properties*.

\begin{tabular}{|c|c|c|c|c|}
\hline Material & Batch number & $\begin{array}{c}\text { Chemical composition } \\
\text { (\% mass) }\end{array}$ & $\begin{array}{c}\text { Flexural Resistance } \\
\text { (MPa) }\end{array}$ & $\begin{array}{l}\text { Coefficient of thermal } \\
\text { expansion }\left(10^{-6} \mathrm{~K}^{-1}\right)\end{array}$ \\
\hline IPS e.max Press & L51815 & $\begin{array}{c}\mathrm{SiO} 2=57 ; \mathrm{Li} 2 \mathrm{O}=11 ; \\
\mathrm{K} 2 \mathrm{O}=6.5 ; \mathrm{P} 2 \mathrm{O} 5=5.5 \\
\mathrm{ZnO}=4 ; \mathrm{ZrO} 2=4\end{array}$ & 400 & 10.15 \\
\hline $\begin{array}{l}\text { IPS e.max Zir- } \\
\text { CAD }\end{array}$ & L10849 & $\begin{array}{l}\mathrm{ZrO} 2=87 ; \mathrm{Y} 2 \mathrm{O} 3=4 ; \\
\mathrm{HfO} 2=1 ; \mathrm{A} 12 \mathrm{O} 3=0.5\end{array}$ & 900 & 10.75 \\
\hline Fit Cast $\mathrm{CoCr}$ & & $\begin{array}{c}\mathrm{Co}=61 ; \mathrm{Cr}=30 ; \\
\mathrm{Mo}=5.9 ; \mathrm{Si}<1 ; \mathrm{Mn}<1\end{array}$ & 721 & 14 \\
\hline IPS e.max Ceram & N18690 & $\begin{array}{c}\mathrm{SiO} 2=60 ; \mathrm{A} 12 \mathrm{O} 3= \\
8 ; \mathrm{Na} 2 \mathrm{O}=6 \mathrm{~K} 2 \mathrm{O}= \\
6 ; \mathrm{ZnO}=2 ; \mathrm{CaO}=2 ; \\
\mathrm{P} 2 \mathrm{O} 5=1 ; \mathrm{F}=0.5\end{array}$ & 90 & 9.5 \\
\hline IPS Inline & & $\begin{array}{c}\mathrm{SiO} 2=59.5 ; \mathrm{A} 12 \mathrm{O} 3=13 ; \\
\mathrm{K} 2 \mathrm{O}=10 ; \mathrm{Na} 2 \mathrm{O}=4\end{array}$ & 80 & 12.6 \\
\hline
\end{tabular}

*According to manufacturer information.

ting was performed in a universal testing machine with a $0.5 \mathrm{~mm}$ thick bevel-shaped rod at a crosshead speed of $0.5 \mathrm{~mm} / \mathrm{min}$ until failure. Data were analyzed statistically by two-way analysis of variance (Anova). Multiple comparisons were made by Tukey's test. $P<0.05$ was considered statistically significant.

Fracture analysis was performed on stereomicroscope (Stemi 2000-C, Carl Zeiss, Gottingen, Germany) and scanning electron microscope (JSM-6380-LV, JEOL, Tokyo, Japan).

Failure modes were classified as: (CV) cohesive failure in the veneer; $(\mathrm{M})$ mixed fracture starting just near the interface, crossing it and continuing in the core; (A) adhesive failure at the core/veneer interface; (CC) cohesive failure in the core.

One additional specimen from each group was longitudinally sectioned for linear scan EDS analysis. It was embedded in an epoxy resin (Araldite, Basel, Switzerland). After $24 \mathrm{~h}$ storage in room temperature the specimens were ground with silicon carbide papers (220-2000 grit size) under continuous water cooling. The specimens were ultrasonically cleaned for $10 \mathrm{~min}$ in a water bath and sputter-coated with carbon in a sputter-coating unit (SCD 004 Sputter-Coater with OCD 30 attachment, BalTec, Vaduz, Liechtenstein). The interfaces were examined in a scanning electron microscopy (SEM) (JEOL 6830LV Microscope). The elemental distribution across the interfaces was determined by using line scan EDS analysis, with a $18 \mu \mathrm{m}$ distance crossing the interface.
Statistical analysis was performed using SPSS statistical package (version 18.0, SPSS Inc., Chicago, USA).

\section{Results}

Results showed similar shear bond strength values before and after thermo and mechanical cycling for all groups (Fig. 1). None of the specimens tested showed debonding during the procedures of aging. The 2-way Anova showed a significant difference for the bond strength among the materials tested at $p<0.05$ (Table 2). Then,

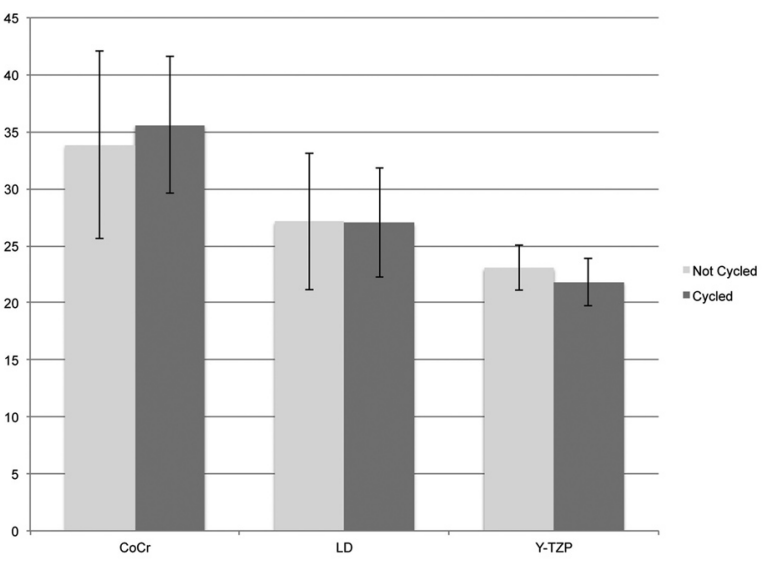

Fig. 1: Shear bond strength results with and without aging for the materials combinations tested (MPa). Vertical bars represent the standard deviation. 
Table 2: Results of two-way analysis of variance for the cycling fatigue conditions, materials, and interaction of shear bond strength data $(p<0.05)$.

\begin{tabular}{|l|c|c|c|c|}
\hline Effect & DF & MS & F & $\boldsymbol{p}$ \\
\hline Materials & 2 & 766.97 & 27.01 & $<0.01$ \\
\hline Cycling & 1 & 0.26 & 0.01 & 0.92 \\
\hline Interaction & 2 & 11.38 & 0.40 & 0.67 \\
\hline
\end{tabular}

Tukey multiple comparisons test was applied to all the specimens within the same material tested $(\mathrm{n}=20)$. The comparisons and the mean shear bond strength for each group are showed in table 3 . Significant differences between all materials were found.

Fracture analysis results are presented in table 4 and distinct failure modes were found for each group. Metal-ceramic group (control) exhibited predominately adhesive failures while lithium disilicate group showed predominately cohesive failure within the core. YTZ-P specimens showed exclusive cohesive failures within the veneering porcelain.

Figure 2 shows the Backscattered Electron Images and the linear scan EDS analysis of the different core/veneer interfaces tested. For group $\mathrm{CoCr}$, decreasing curves of $\mathrm{Co}$ and $\mathrm{Cr}$ densities at metallic phase and increasing $\mathrm{Si}$, $\mathrm{K}$ and $\mathrm{Al}$ of the glass phase were almost monotonic and sigmoidal. There was a superposition for approximately $4 \mu \mathrm{m}$ and the curves of $\mathrm{Si}$ and Co shows a maximum at

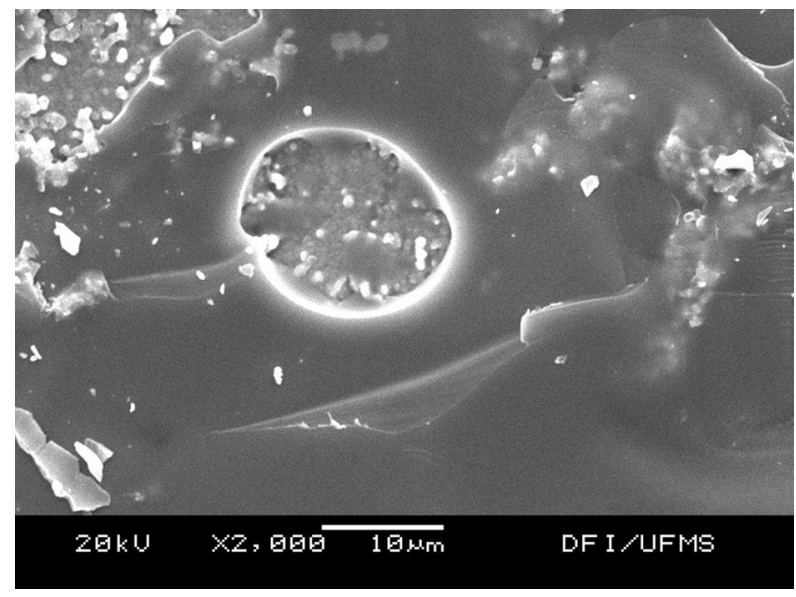

Fig. 2: SEM image of Y-TZP group. Cohesive fractures within veneer ceramic were evidenced due to the presence of a thin layer of porcelain attached to core.

the center of the interface while $\mathrm{Cr}$ was minimum. For LD group the density variation of elements was smoother and the interdiffusion at interface was approximately $10 \mu \mathrm{m}$. The core/veneer interface in YTZ-P group is very defined and regular, which indicates a lesser superposition and greater chemical and structural homogeneity of each material. The transition curves of EDS analysis embrace about $3 \mu \mathrm{m}$.

Table 3: Shear bond strength (MPa) means and standard deviation (SD) and comparisons* between the materials combinations tested.

\begin{tabular}{|l|c|c|c|c|c|c|}
\hline & \multicolumn{2}{|c|}{ Materials } & & & \\
\hline Grupo & Core & Veneer & $\mathrm{n}$ & Mean & SD & $*$ \\
\hline $\mathrm{CoCr}$ & Fit Cast CoCr & IPS Inline & 20 & 34,72 & $\pm 7,05$ & $\mathrm{a}$ \\
\hline LD & IPS e.max Press & IPS e.max Ceram & 20 & 27,07 & $\pm 5,28$ & $\mathrm{~b}$ \\
\hline Y-TZP & IPS e.max ZirCAD & IPS e.max Ceram & 20 & 22,46 & $\pm 2,08$ & $\mathrm{c}$ \\
\hline
\end{tabular}

*Means followed by the same letter in a column are not significantly different according to Tukey's test at 5\% probability level.

Table 4: Failure modes for each group (values in \%): (CV) Cohesive failure in the veneer, (M) Mixed fracture, (A) Adhesive failure at the core/veneer interface, (CC) Cohesive failure in the core.

\begin{tabular}{|l|c|c|c|c|}
\hline & \multicolumn{4}{|c|}{ Failure mode } \\
\hline Group & A & CV & CC & M \\
\hline CoCr & 85 & 5 & - & 10 \\
\hline LD & - & - & 65 & 35 \\
\hline Y-TZP & - & 100 & - & - \\
\hline
\end{tabular}

\section{Discussion}

Regardless of the materials tested, the thermal and mechanical cycling protocol adopted in the present study did not have influence the core/veneer bond strength, thus the first null hypothesis tested was not rejected (Table 2). Thermo cycling has been used to simulate that condition in in vitro tests and, in some studies, leads to spontaneous debonding of the specimens or reduction of bond strength (12). Mechanical fatigue from of chewing also may contribute to clinical failure, since it subjects restorative materials themselves or their interfaces to re- 
peated stresses. Since no influence of the aging protocol used in the present study was found, it can be concluded that the different interfaces tested resisted the mechanical and thermal stresses to which they were subjected and are able to resist fatigue-challenging situations.

Significant differences between shear bond strength of the materials tested were found. Thus, the second null hypothesis was rejected. The control group $(\mathrm{CoCr})$ showed mean shear bond strength of $34.72 \mathrm{MPa}$, satisfactory value for metal ceramic interface bond strength according to the International Organization of Standardization that proposed a minimum value of $25 \mathrm{MPa}$ for these systems. Failure mode was predominately adhesive. EDS analysis showed an interaction zone along the interface between the $\mathrm{CoCr}$ substrate and the opaque porcelain. It can be inferred that ions inter-diffusion oc- curs at the interface characterizing a chemically adhesive process predominantly by $\mathrm{Si}$ and Co inter-diffusion. Anusavice et al. (15) have also described this chemical interaction and suggested that there is an interaction between $\mathrm{Cr}$ ions of the $\mathrm{Cr} 2 \mathrm{O} 3$ at the core material and the $\mathrm{Al}$ provided by the opaque porcelain, forming a mixed complex of Al-Cr-O, which leads to a strong adhesion between the materials.

YTZ-P group showed mean shear bond strength of 22,46 MPa and failure mode predominantly cohesive within the veneering porcelain. Fracture analysis with SEM was mandatory to determine the failure mode, since a very thin layer of veneering porcelain was attached to the YTZ-P core (Fig. 2) and it was challenging to distinguish it in the optical microscope. SEM images of the interfaces (Fig. 3) showed a well-defined boundary bet-
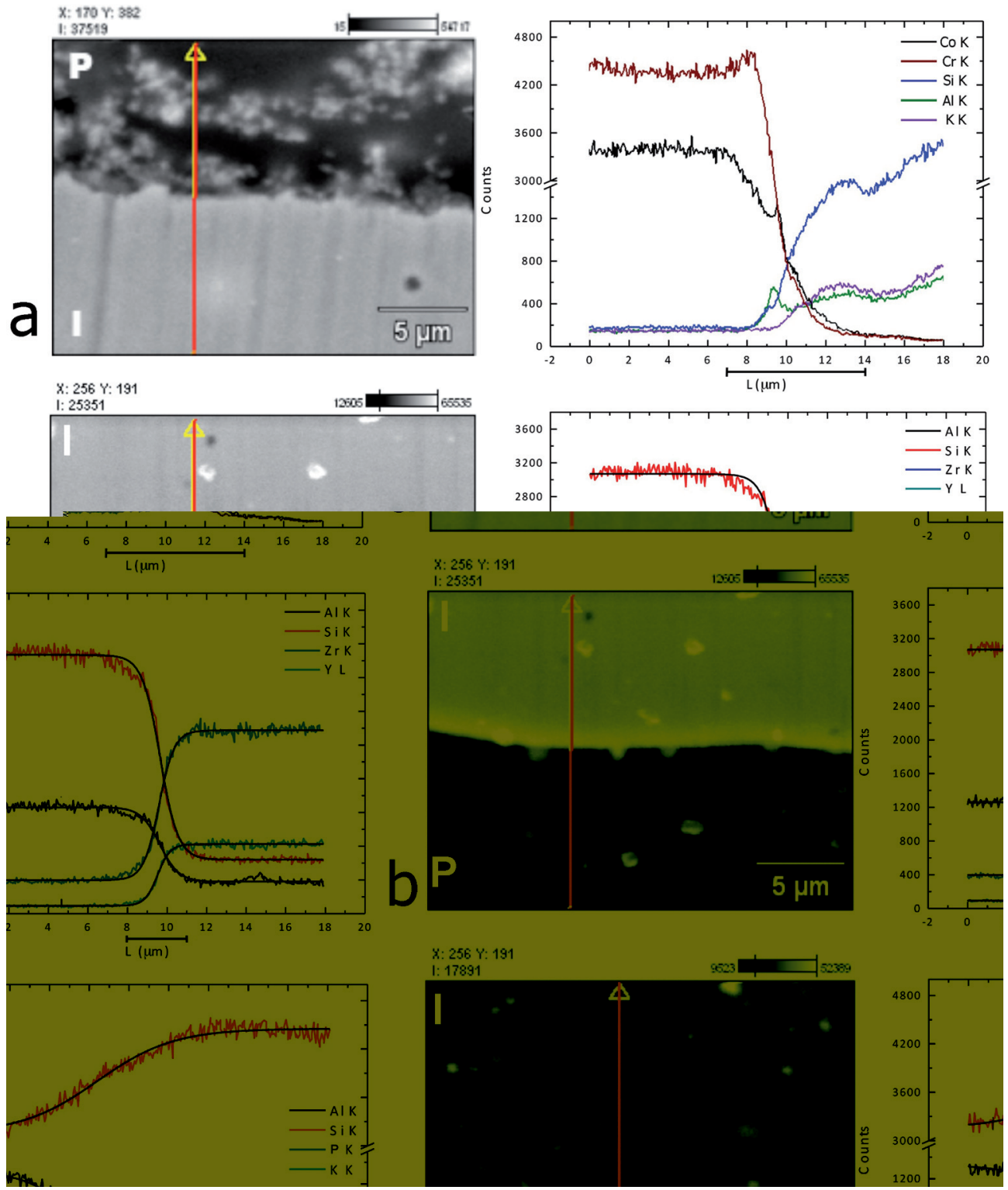

Fig. 3: Line scan EDS analysis demonstrating the variation of each element across the different interfaces $(\mathrm{a}-\mathrm{CoCr}$; $\mathrm{b}-$ YTZ-P; $\mathrm{c}-\mathrm{LD}$ ). The horizontal bars bellow the " $\mathrm{X}$ " axis represents the interaction zone. 
ween the two materials. Although EDS analysis showed a possible $3 \mu \mathrm{m}$ zone of elemental curves variation, it cannot be stated, based on that data, that there is an interaction zone between materials. Since the electron beam has approximately $1 \mu \mathrm{m}$, it can be considered that the behavior of increasing and decreasing element densities curves may be related to the superposition of the electron beam. Thus, each measure may be a spatial mean of the composition and not necessarily of a real density variation of the elements. Thus, it is not clear, based on the results, if there is an actual chemical interaction between YTZ-P and veneering porcelain. However, other reports (17-19) strongly suggest it. Tholley et al. (19) found morphological changes and tetragonal to monoclinic transformation in the zirconia core material in contact with the veneering porcelain that may indicate that there is some sort of chemical interaction between these materials. Durand et al. (17) reported, through Raman Imaging Analysis, an interaction zone that ranges from approximately $1.3 \mu \mathrm{m}$ to $3 \mu \mathrm{m}$. The actual chemical interaction mechanisms, however, is yet to be confirmed.

LD group showed mean shear bond strength of 27.07 and failure mode predominantly cohesive within the core similar to the findings of Al-Dohan et al. (9) and Ereifej et al. (11). SEM images (Fig. 3) showed no defined interface between the materials compared to the other groups and EDS analysis showed an interaction zone of approximately $10 \mu \mathrm{m}$. This may be explained by the similar chemical composition and elemental concentration of the core material and the veneering porcelain (Table 1) that would promote a complete chemical interaction forming a continuum between the two materials, instead of a well-defined interface.

In the present study, thermal and mechanical cycling did not have influence on the shear bond strength of the ceramics systems tested, suggesting that those interfaces has a good stability after induced thermal and mechanical induced stresses.

\section{References}

1. Kelly JR. Dental ceramics: what is this stuff anyway? J Am Dent Assoc. 2008;139:4S-7S.

2. Thompson JY, Anusavice KJ, Naman A, Morris HF. Fracture surface characterization of clinically failed all-ceramic crowns. J Dent Res. 1994;73:1824-32.

3. Sailer I, Pjetursson BE, Zwahlen M, Hammerle CH. A systematic review of the survival and complication rates of all-ceramic and metal-ceramic reconstructions after an observation period of at least 3 years. Part II: Fixed dental prostheses. Clin Oral Implants Res. 2007;18:86-96. 4. Silva NR, Thompson VP, Valverde GB, Coelho PG, Powers JM, Farah JW, et al. Comparative reliability analyses of zirconium oxide and lithium disilicate restorations in vitro and in vivo. J Am Dent Assoc. 2011;142:4S-9S.

5. Aboushelib MN, Feilzer AJ, Kleverlaan CJ. Bridging the gap between clinical failure and laboratory fracture strength tests using a fractographic approach. Dent Mater. 2009;25:383-91.

6. Aboushelib MN, de Jager N, Kleverlaan CJ, Feilzer AJ. Microtensile bond strength of different components of core veneered all-ceramic restorations. Dent Mater. 2005;21:984-91.
7. Aboushelib MN, Kleverlaan CJ, Feilzer AJ. Microtensile bond strength of different components of core veneered all-ceramic restorations. Part II: Zirconia veneering ceramics. Dent Mater. 2006;22:85763.

8. Zheng Z, Lin J, Shinya A, Matinlinna JP, Botelho MG. Finite element analysis to compare stress distribution of gold alloy, lithium-disilicate reinforced glass ceramic and zirconia based fixed partial denture. J Investig Clin Dent. 2012;3:291-7.

9. Al-Dohan HM, Yaman P, Dennison JB, Razzoog ME, Lang BR. Shear strength of core-veneer interface in bi-layered ceramics. J Prosthet Dent. 2004;91:349-55.

10. Lopez-Molla MV, Martinez-Gonzalez MA, Manes-Ferrer JF, Amigo-Borras V, Bouazza-Juanes K. Bond strength evaluation of the veneering-core ceramics bonds. Med Oral Patol Oral Cir Bucal. 2010;15:919-23.

11. Ereifej N, Rodrigues FP, Silikas N, Watts DC. Experimental and FE shear-bonding strength at core/veneer interfaces in bilayered ceramics. Dent Mater. 2011;6:590-7.

12. Vasquez VZ, Ozcan M, Kimpara ET. Evaluation of interface characterization and adhesion of glass ceramics to commercially pure titanium and gold alloy after thermal- and mechanical-loading. Dent Mater. 2009;25:221-31.

13. Oyafuso DK, Ozcan M, Bottino MA, Itinoche MK. Influence of thermal and mechanical cycling on the flexural strength of ceramics with titanium or gold alloy frameworks. Dent Mater. 2008;24:351-6.

14. Kelly JR. Clinically relevant approach to failure testing of all-ceramic restorations. J Prosthet Dent. 1999;81:652-61.

15. Anusavice KJ, Ringle RD, Fairhurst CW. Adherence controlling elements in ceramic-metal systems. II. Nonprecious alloys. J Dent Res. 1977;56:1053-61.

16. Zinelis S, Barmpagadaki X, Vergos V, Chakmakchi M, Eliades G. Bond strength and interfacial characterization of eight low fusing porcelains to cp Ti. Dent Mater. 2010;26:264-73.

17. Durand JC, Jacquot B, Salehi H, Margerit J, Cuisinier FJ. Confocal Raman microscopy and SEM/EDS investigations of the interface between the zirconia core and veneering ceramic: the influence of a liner and regeneration firing. J Mater Sci Mater Med. 2012;23:1343-53.

18 . Tholey MJ, Berthold C, Swain MV, Thiel N. XRD2 micro-diffraction analysis of the interface between Y-TZP and veneering porcelain: role of application methods. Dent Mater. 2010;26:545-52.

19. Tholey MJ, Swain MV, Thiel N. SEM observations of porcelain Y-TZP interface. Dent Mater. 2009;25:857-62.

20. Vidotti HA, Pereira JR, Insaurralde E, de Almeida AL, do Valle AL. Thermo and mechanical cycling and veneering method do not influence Y-TZP core/veneer interface bond strength. J Dent. 2013;41:30712.

Acknowledgements

The authors thank the financial support by FAPESP (Fundação de Amparo à Pesquisa do Estado de São Paulo - Grant number: 2009/17066-9 and 2009/03892-4) and specially thank Romanini Dental Laboratory (Londrina/Brazil) for the technical support. 